REMARKS ON TIIE

STATE OF THE VESSELS OF THE PIA MATER IN BRIGHT's DISEASE ("ARTERIOCAPILLARY FIBROSIS").

By A. G. AULD, M.D.

From the Pathological Laboratory of the Western Infirmary, Glasgow)

Iv the course of the past eighteen months I have examined the vessels of the pla mater in all (or nearly all) brains removed for examination in the post-mortem room of the infirmary during that period. In each case the pia mater was hardened for a long time in Müller's fluid, and after. wards in alcohol. The method adopted for examining the coats of the vessels consisted in washing out the alcohol, soaking in gum and sugar solution for a few days, then freezing the membrane en masse, and cutting sections. It cannot be said that the resulting sections were the best that could bedesired from an artistic point of view; but after careful staining and mounting, I have made out by means of high powers what appears to be the trae nature of the "hyalinefibroid" thickening of Gull and Satton. As is well known, these authors, in their celębrated papers, contended that in chronic Bright's disease the vessels throughout the body generally, and especially those in the pia mater, har their outer coats thickened by a "hyaline-fibroid material," while the muscular coat sho wed atrophic changes, and the tunica intima was generally unaltered, though oceasionally thickened. With respect to the muscular coat, such an atrophy has generally been denied, and Johnsou especially laid stress on a true hypertrophy of this layer, quite apart from any question of an apparent hypertrophy from contraction oscurring at deatn. On the other hand, all observers are agreed as to a thickening of the outer coat. First, as regards the larger vessels, my observations go to show that in Bright's disease (though not limited to this affection) a hypertrophy of all the coats is the condition most generally observed, and of the three, that most frequently excepted from bypertrophy is the inner, while that most constantly involved is the outer. The thickening of the inner coat consist 3 in an endarteritis, such as forms the first stage of atheroma, causing the intima to be represented by a more or less thick and unequal layer of very cellular tissue-a tissue pro. duced by a rank cellular proliferation. This was very characteristic of cases presenting the atrophic stage of large white kidney, and was not so pronounced in cases of ordinary granular kidney. As regards the muscular layer, in most of the cases there was undoubted increase of the muscle nuclei. There was then always hypertrophy of the left ventricle of the heart. In a few cases the muscular layer showed a degree of atropby, unequally distributed, and some fatty degeneration of its cells; there was then usually some fatty change in the heart. Occasionally not much alteration from the normal was detected. With respect to the condition of the outer coat, as stated, all observers agree that this coat is thickened, and sometimes very greatly so, in the cases under consideration. It presents in the arteries and arterioles alike a homogeneous, somewhat translucent, aspect, which in the larger vessels is particularly marked in that portion which lies nearest the muscularis. Gall and Sutton held that there was a deposition or formation of a "hyaline-fibroid" subatance, giving this coat the appearance described by Dickinson, "as if swollen with translucent structureless exudation." Johngon and others considered this hyaline appearance to ba a delusive result of reagents-e.g., glycerine, acidulated mounting flaids. In any case, the cause of the byaline-fibroid formation has nob so far been determined. Now I have invariably made out by means of oll.immersion objectives ( $Z$ eise) the existence of branched corpuseles with large and fre quently divided nuclei embedded in this hyaline-fibroid substance. Further, after maceration in picric acid and exerting pressure over the cover-glass this homogeneouslooking layer was seen at the cut extremity of the vessel to be split up into exceedingly fine fibrils. In short, it was clearly demonstrated that this formation is ordinary connective tissue derived from connective-tissue corpuseles after the manner of inflammatory tissue. And not only in the outer conts of the vessels, but likewise throughout the whole tissue of the pia mater, this corpuscular change was usually seen, leading to a more or less general thickening.

From these observations it is to be concluded: 1 . The hyaline-fibroid thickening of the outer coat of the vessels is not of the nature of an exudation or deposition of a foreign substance. nor yet a transformation of existing structures. 2. The effect of reagents is, after all, but unimportant. 3. The thickening of the outer coat is unquestionably due to proliferation of connective-tissue corpuscles embedded therein, leading to new formation of tisene; in short, is a slowly progressing periarteritis. 4 This change is probably general throughout the entire tissue of the pia mater. 5. The muscular and inner layers of the vessels show hyperplastic changes at first; latterly atrophic and degenerative changes set in.

In the case of the smaller arterioles their muscular elements were certainly increased in volume, if nob al so in number, and their delicate investment of connective tissue was represented by a thick, homogeneous-looking cylinder. It is particularly to be noted, however, that their endothelial lining showed no deviation from the normal, in this respect presenting a marked contrast to the condition prevailing in the larger vessele. The diameter of the channels in these thickened arterioles suffered great diminution; not inf equently it measured just the diameter of the wall. Such a diminution suggests an adequate explanation of the cardiac hypertrophy in chronic Bright's disease. I hope, however, to return to the consideration of this point.

In conducting these observations, I may say that it was impassible not to be struck with the marvellous advance made in this department of pathology by the distinguished authors of "arterio capillary fibrosis."

Glasgow.

\section{PLACENTITIS AND MISCARRIAGE.}

\section{By CHARLES GAYFORD, M.D. DUR., M.R.C S., \&:。}

THIs case is one of more than ordinary interest, and will doubtless be of service to other members of the profession.

On Feb. 13 th I was summoned hastily to see Mrs. Cwhom $I$ found seated on a commode in which was lying a foetus of about five months. She said the expulsion had come on quite suddenly, though she had been ailing for some weeks. The following history was elicited. On Boxing-day she had shivering and great headache, but she did not go to bed. A day or two after, while still feverish and in some pain, she came on unwell, and lost freely for two days, more than at ordinary monthly periods. The loss then lessened, and she, still keeping about, thought she must have made a mistake in her opinion as to pregnancy. A second loss occurred a few days subsequently, followed by a very copious discharge of "whites." Still she kept about, though often feeling extremely ill and unfio for her duties, which were those of a matron of a boys' home. In this way some five weeks passed before the mishap occurred for which I was called in, and during this time sbe had only once seen a doctor. She had all the time been in failing health. On my arrival I severed the cord, which was bloodless; and the foetus, which was discoloured, had probably been dead several days. There was no trace of any membranes, nor was there any evidence of amniotic fluid. After getting the patient on to the bed I examined her for the purpose of removing the placenta. I could trace the cord up to the point of attachment on the uterine wall, which presented at that point a puckered, rough, and somewhat hard surface, but no further evidencs of the presence of a placenta. After waiting a litble time for uterine contractions to come on, as I had given ergot, I made a further attempt to get the placenta away, but in vain. The cord was firmly attached, and any force seemed likely, owing to the condition of inertia in which the uterus was, to bring about prolapsus, if not inversio uteri I left my patient for a time, with orders to call me at once if any need arose. After an interval of an hour I saw her again, when the same state of things wasfound. There had been no pains and there was no hæmorrhage, nox had the cord become detached. After giving another drachm 
dose of ergot I left, giving instructions to be called at once it necessary. This time I was two hours away before calling, and when I arrived found a considerable amount of hæmorrhage. I emptied the uterus, removing several clots, which were small and all carefully examined, and in doing so, without using any but the gentlest traction, the cord got released from its attachment and came away. It showed evidence of attachment to what had been placenta merely. It was spread out to about the size of a two-shilling piece. Its abtachment showed nothing more than a spreading out of the outer covering of the cord; there was no evidence of membranes or any portion of placenta attached to it. There was the same condition of uterine wall. The hremorrhage ceased, and I left my patient, to be seen again later in the day. I ordered the use of an injection of 1 in 5900 bichloride of mercury solution and a mixture of bromide of potassium and liquid extract of ergot. The next day her temperabure was $1002^{\circ} \mathrm{F}$, but it went back to normal in the evening and remained so during the whole of the convalescence, which was uninterrupted. I allowed her to get up on the fourteenth day, and she has since been about as nual. There was no placenta discharged, no hæmorrhage after the one I have spoken of, nor any ill-smelling discharges. At the month after the occurrence she had a slight flow, bat notbing to speak of, for two days. At the next period she lost freely for three days. She has resumed and still continues her somewhat arduous duties, and is in good health.

My diagnosis in this case was miscarriage following placentitis. My belief is that she had influenza tbe week after Christmas, and that this set up the trouble. This is her fifth pregnancy. There is no evidence of specific mischief, though she has been singularly unfortunate. Two of four children were born at full time dead. Shoulder presentations. The others were one shoulder and one breech presentation, both of whom are living and healthy children. Both parents are young people and healthy. I should be glad to hear of any similar experience, for my own feeling is that the evil effects of the so.called influenza show mischievous ramifications so widespread that hardly any portion of the body can claim immunity from its ravages. Fleet-street, E.C.

\section{ACUTE INTESTINAL OBSTRUCTION; OPERATION BY SHORT CIRCUIT. ${ }^{1}$}

BY EDWARD ATKINSON,

SENIOR SURGEON TO THE LEEDS GENERAL INFIRMARY.

G. F- aged towenty-two, was admitted into the General Infirmary, under Dr. Churton, on Wednesday, Nov. 25th, suffering severe pain in the right side of the abdomen. In Dr. Churton's absence Dr. Jacob asked me to see the patient with him, when the following history was elicited:-Nine days previously he was seized with severe pain in the epigastrium and right side of the abdomen. He left his work and remained at home two days, taking castor oil and other medicines, which were vomited, together with all the food that he took. The third day, feeling better, he went to work again for two days, when the symptoms returned, and on Friday, the 20th, he kept his bed. The next day acute pain came on and vomiting, nothing having passed the bowels for some days. On the Sunday he passed a small motion and felt somewhat better for it, but on Monday the pain and vomiting returned, and lasted without intermission till his admission on Wednesday afternoon (the $25 \mathrm{th}$ ), and no more motion had passed. On examination the abdomen was tense and tympanitic especially on the right side. The patient complained of pain of a sickening character right across the hypogastrium, and hehad manifest tenderness on pressure overalimited area in the right iliac region. There was resonance over the whole abdomen, and the movements of the small intestine could be distinctly seen. The patient said he had passed a little flatus in the morning, but two enemata given him after being admitted into hospital had not been followed by any further relief. The symptoms seemed partly to point to the cacum or vermiform appendix, bab the vermicular movement

1 A paper read on Dec. 18th, 1891, before the Leeds and West Riding 1 A paper read on Dec. 18
Medico-Chirurgical Society. of the small intestine suggested that the obstruction was higher up. However, the fact that he had had no opiate, and his statement of having passed a little flatus, induced me to order a hypodermic in jection of morphia, as it was late at night, and to wait till the morning. The next day he was no better, and so I resolved to explore. At 10 A.M.s. under chloroform, I made an incision five inches long over the outer border of the right rectus muscle. On opening the peritoneum a quantity of clear fluid escaped. Nothing suggestive of typhlitis or perityphlitis was found, but distended coils of small intestine presented at the wound. These were united to one another and to the iliac fossa by broad bands of adhesion, not recent, and prevented my being able to draw them forward or trace their course. These bands were evidently not the cause of obstruction. Being unable to see or feel any large intestine, I carefully tied and divided one or two of the broad bands, which. enabled me to turn aside a coil of small intestine, and then. found the cxecum behind it empty. It being now evident that the matting of the bowels rendered any further search. for the cause of the obstruction impossible, the only course which seemed available was to bring the small intestine out of the wound and make an artificial anus; but Mr. Littlewood, who was present, suggested to me that the expedient of shoro circuiting, which he had performed in the ease which he read to the Society a fortnight ago, would be equally applicable here. Accordingly I opened the collapsed colon, as much above the cecum as I could reach, and inserted a Senn's bone plate; and after isolating the nearest coil of ileum, and securing it by tying a piece of indiarubber tubing round it, I opened it and inserted the corresponding plate. The large and small gut, being now brought into apposition, were further secured by marginal sutures around the plates, and the peritoneal wound was closed with deep silk sutures and silkworm gut for the external wound. Altogether the operation lasted an hour and a quarter. Within twelve hours after the patient had two Jarge liquid motions, and next morning he expressed himself as feeling quite comforta able. His recovery has been uninterrupted, except for an abscess in the abdominal wall about a week afterwards, which soon cleared up. He was kept without food for three days, then small quantities of milk were allowed, and in a week afterwards he took rice pudding and mincemeat, and is now on ordinary dieb.

Io will readily be seen how immense an advance this procedure offers in the treatment of those cases of acute obstruction where the cause is, after careful search, either undiscovered or out of reach; and which otherwise would have to be relegated to the category of incurable cases, or dealt with by the formation of an artificial anus. With this new departure one may hope that few cases of obstruction will arise in which relief is unattainable, if treated in time. Leeds.

A CASE OF

SECONDARY CANCER OF THE RIB, VERTEBR $A$, AND OVARY,

OCCURRING AFTER REMOVAL OF THE PRIMARY DISEASE IN THE MAMMA, AND COMPLICATED BY MYOMA OF THE UTERUS.

(From the Pathological Laboratory of the Glasgow Royat. Infirmary.)

BY JOHN LINDSAY STEVEN, M.D., PATHOLOGIST, GLASGOW ROYAL INFIRMARY;

$$
\text { AN D }
$$

JOHN BROWN, M.D.,

DISPENSARY SURGEON, GLASGOW SAMARITAN HOSPITAL FOR WOMEN,

THE following case is of interest as affording an illustration of the recurrence of mammary cancer in the bones, It is unforbunate that no accurate and exhaustive clinical record of the earlier period of the case is now possible, as the operation was performed at the patient's home, and $F$ have been able to obtain only very meagre information as to the opinion held at the time regarding the nature of the primary bumour.

Mrs. C-, aged forty-six, housewife. The patient has had two children, both delivered by instruments; the last, 